\title{
Direct UV written Michelson interferometer for RZ signal generation using phase-to- intensity modulation conversion
}

Peucheret, Christophe; Geng, Yan; Zsigri, Beata; Sørensen, Henrik Rokkjær; Chi, Nan; Deyerl, HansJürgen; Kristensen, Martin; Jeppesen, Palle

Published in:

I E E E Photonics Technology Letters

Link to article, DOI:

10.1109/LPT.2005.851930

Publication date:

2005

Document Version

Publisher's PDF, also known as Version of record

Link back to DTU Orbit

Citation (APA):

Peucheret, C., Geng, Y., Zsigri, B., Sørensen, H. R., Chi, N., Deyerl, H-J., Kristensen, M., \& Jeppesen, P. (2005). Direct UV written Michelson interferometer for $R Z$ signal generation using phase-to-intensity modulation conversion. I E E E Photonics Technology Letters, 17(8), 1674 - 1676. https://doi.org/10.1109/LPT.2005.851930

\section{General rights}

Copyright and moral rights for the publications made accessible in the public portal are retained by the authors and/or other copyright owners and it is a condition of accessing publications that users recognise and abide by the legal requirements associated with these rights.

- Users may download and print one copy of any publication from the public portal for the purpose of private study or research.

- You may not further distribute the material or use it for any profit-making activity or commercial gain

- You may freely distribute the URL identifying the publication in the public portal 


\title{
Direct UV Written Michelson Interferometer for RZ Signal Generation Using Phase-to-Intensity Modulation Conversion
}

\author{
Christophe Peucheret, Yan Geng, Mikael Svalgaard, Beáta Zsigri, Henrik Rokkjær Sørensen, Nan Chi, \\ Hans-Jürgen Deyerl, Martin Kristensen, and Palle Jeppesen, Member, IEEE
}

\begin{abstract}
An integrated Michelson delay interferometer structure making use of waveguide gratings as reflective elements is proposed and fabricated by direct ultraviolet writing. Successful return-to-zero alternate-mark-inversion signal generation using phase-to-intensity modulation conversion is demonstrated up to $40 \mathrm{~Gb} / \mathrm{s}$ using the device. Compared to other implementations, the device is compact, inherently stable, and allows for easy customization of the pulsewidth by proper positioning of the gratings on a single coupler structure.
\end{abstract}

Index Terms-Delay interferometer (DI), direct ultraviolet (UV) writing, integrated optics, return-to-zero (RZ) generation.

\section{INTRODUCTION}

D IRECT ultraviolet (UV) writing is a promising technique for the fabrication of optical waveguide components due to its simplicity compared to conventional clean room processing and its potential for large-scale production at a reduced cost [1]. Low-loss and low-birefringence waveguides have been fabricated, and a number of functionalities such as directional couplers, splitters [2], [3], and variable optical attenuators [4] have been demonstrated.

From the systems technology side, a tremendous research effort has been devoted over the past few years to the generation and investigation of the properties of novel modulation formats. Among those, the return-to-zero (RZ) alternate-mark-inversion (AMI) format has been shown to result in improved optical fiber nonlinearity tolerance over conventional ON-OFF keying at $40 \mathrm{~Gb} / \mathrm{s}$ [5]. This format can be generated using phase modulation followed by a delay interferometer (DI) [6]-[9]. The method is cost effective since it enables optical RZ signal generation from conventional nonreturn-to-zero (NRZ) electronics and only requires a single phase or dual-drive Mach-Zehnder

Manuscript received April 21, 2005.

C. Peucheret, Y. Geng, M. Svalgaard, B. Zsigri, H. R. Sørensen, N. Chi, and P. Jeppesen are with the Research Center COM, Technical University of Denmark, Kgs. Lyngby DK-2800, Denmark (e-mail: cp@com.dtu.dk; yg@com.dtu.dk; svlgrd@com.dtu.dk; bz@com.dtu.dk; hrs@com.dtu.dk; eeznc@bristol.ac.uk; pj@com.dtu.dk).

H.-J. Deyerl was with the Research Center COM, Technical University of Denmark, Kgs. Lyngby DK-2800, Denmark. He is now with Institut für Physik, Technische Universität Chemnitz, Chemnitz D-09107, Germany (e-mail: hansjuergen.deyerl@physik.tu-chemnitz.de).

M. Kristensen was with the Research Center COM, Technical University of Denmark, Kgs. Lyngby DK-2800, Denmark. He is now with Institute of Physics and Astronomy, Aarhus University, Århus C DK-8000, Denmark (e-mail: mk@phys.au.dk).

Digital Object Identifier 10.1109/LPT.2005.851930

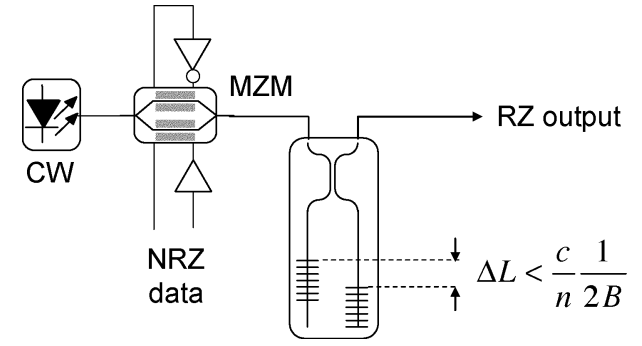

Fig. 1. Principle of operation of the RZ transmitter and structure of the proposed Michelson grating DI.

modulator (MZM). It is also flexible since the pulsewidth can be tailored by the choice of a proper delay. Planar lightwave circuit DIs based on the Mach-Zehnder structure are inherently stable and compact devices suitable for practical implementation in transmitter modules. However, generation of RZ pulses with a sufficiently high extinction ratio is only feasible at the price of a precise control of the coupling ratio of two 3-dB couplers, which might limit the fabrication yield of such devices. Furthermore, a totally new device design is required for each targeted pulsewidth, corresponding to a given delay, when such a Mach-Zehnder structure is used.

In this letter, we demonstrate a DI structure based on a direct UV written Michelson interferometer where the reflective elements are realized by waveguide gratings. The structure is simple since it consists of a single $3-\mathrm{dB}$ coupler with waveguide gratings written in each arm. It is furthermore compact and allows for easy customization of the pulsewidth by simply adjusting the position of the gratings in the arms of a single coupler structure. Using the fabricated device, we demonstrate successful RZ-AMI signal generation at up to $40 \mathrm{~Gb} / \mathrm{s}$.

\section{PRINCIPLE OF OPERATION}

The structure of the RZ transmitter (shown in Fig. 1) is similar to the one proposed in [9]. An MZM driven in push-pull mode by differentially encoded NRZ data and inverted data at a bit rate $B$ is used to generate phase modulation with instantaneous $\pi$ phase shifts. A DI with delay smaller than the bit slot duration $1 / B$ converts the phase modulation to intensity modulation and generates an RZ signal whose pulse full-width at half-maximum (FWHM) depends on the value of the delay and the modulation rise time [9]. Fig. 2 shows the calculated RZ pulsewidth as a function of the interferometer delay for different values of the NRZ electrical signal rise time. Our calculations 


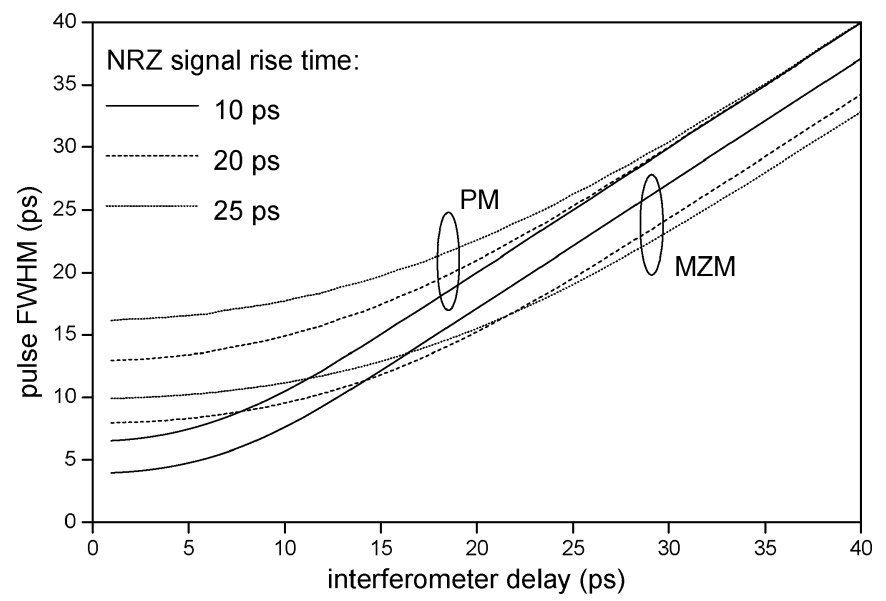

Fig. 2. Calculated pulse FWHM as a function of interferometer delay for different values of the NRZ signal rise-time for phase modulated signal generation using a phase modulator (PM) or an MZM.

confirm previous observations in [6] and [9], especially the different dependence of the pulsewidth on the delay depending on whether phase modulation is achieved in a phase modulator or a Mach-Zehnder intensity modulator biased at a null transmission point and driven between two consecutive maxima of its power transfer function. Fig. 2 allows the determination of the delay required to achieve a given pulsewidth, hence, the physical length difference between the interferometer arms, depending on the phase modulated signal generation method.

Our DI structure consists of a Michelson interferometer made from a coupler and two waveguides, all UV written, where reflective elements are implemented as intracore Bragg gratings. The delay is set by the path length difference accumulated for forward and backward propagation after reflection by the gratings, improving the compactness of the device compared to a conventional Mach-Zehnder structure. The influence of residual birefringence in the waveguides and grating is reduced as the device is implemented at the transmitter side, where polarization-maintaining connections would be used. Furthermore, compared to the Mach-Zehnder DI structures used until now, a single coupler is required, hence resulting in a better fabrication yield for devices achieving a required extinction ratio. As the same coupler is used for splitting and combining the incoming phase modulated signal, the extinction ratio does not depend on the coupling ratio, but only on the relative reflectivities of the two waveguide gratings. Finally, the same basic coupler structure can be used to realize a variety of RZ signal pulsewidths since the delay simply depends on the relative position of the two waveguide gratings in each arm of the coupler. However, unlike Mach-Zehnder DIs that can easily be tuned to different channel wavelengths due to the periodicity of their transfer functions, the limited bandwidth of the reflectors in our proposed structure requires customization of the device for a given channel or channel range. Note that Fig. 2 had assumed wavelength-independent attenuation for the two paths constituting the DI. This is typically the case for a Mach-Zehnder DI structure, but might need to be corrected for our proposed Michelson structure in case the bandwidth of the gratings becomes comparable to the spectral width of the phase modulated signal.

\section{DEVICE FABRICATION AND PROPERTIES}

The Michelson interferometer was UV written by scanning a photosensitive sample fabricated by plasma-enhanced chemical vapor deposition under a focused UV beam [10]. The sample consisted of a silica-on-silicon structure containing Ge and B in the 5.5- $\mu \mathrm{m}$-thick waveguide core layer [3] that had been deuterium loaded in order to increase its photosensitivity. The coupler was written with a UV beam (width: $3 \mu \mathrm{m}$ at $1 / e^{2}$ ) at $257 \mathrm{~nm}$ from a frequency doubled argon-ion laser. The incident UV power was $45 \mathrm{~mW}$ and the applied scan speed was $200 \mu \mathrm{m} / \mathrm{s}$, resulting in 6.2- $\mu \mathrm{m}$-wide waveguides with an index step of 0.006. One side of the coupler contained 2-cm-long waveguides spaced $250 \mu \mathrm{m}$ apart to accommodate the Bragg gratings, giving a total component length of $3 \mathrm{~cm}$. The measured insertion loss of a straight reference waveguide was $0.65 \mathrm{~dB}$ with a polarization-dependent loss of $0.25 \mathrm{~dB}$. The waveguide center-to-center spacing in the central coupling region was $13 \mu \mathrm{m}$. The coupler excess loss was $0.2 \mathrm{~dB}$ and the coupling ratio was 0.8 . As mentioned previously, this value does not impact the extinction ratio of the pulses but only affects the transmitted power. The coupling loss to standard single-mode fiber was less than $0.2 \mathrm{~dB}$ per facet, leading to a fiber-to-fiber loss of about $9 \mathrm{~dB}$. A significant advantage of using the direct UV writing technique is that the same setup used for waveguide fabrication can be used for grating fabrication. To do this, the incident beam diameter was increased to $70 \mu \mathrm{m}$ and a phase mask [11] was placed in direct contact with the sample. By appropriately scanning the sample, the location and extent of the gratings can be precisely controlled. In this way, 4-mm-long uniform gratings were written into each coupler arm with a relative displacement of $2.406 \mathrm{~mm}$, so that a delay of $23 \mathrm{ps}$ is achieved. The gratings had an attenuation in the stopband in transmission of 45 and $46 \mathrm{~dB}$ and a bandwidth of $80 \mathrm{GHz}$. Furthermore, the polarization-dependent wavelength shift of the interferometer transfer function was measured to be $0.02 \mathrm{~nm}$.

\section{RZ SIGNAL GENERATION}

The performance of the fabricated device was evaluated at $10,20,30$, and $40 \mathrm{~Gb} / \mathrm{s}$. The experimental setup is similar to the one represented in Fig. 1. As a pseudorandom binary sequence (PRBS) was used, no differential encoding of the data was performed prior to phase modulation. After RZ signal generation in the Michelson DI, the signal was preamplified by an erbium-doped fiber amplifier and detected in a photodiode with $50-\mathrm{GHz}$ bandwidth. The same receiver configuration was used independently of the bit rate. In practice, phase tuning of the interferometer can be achieved using a heating element. In the present demonstration, the tunability of the laser source was exploited instead. Successful RZ signal generation was achieved at the output of the DI up to $40 \mathrm{~Gb} / \mathrm{s}$, as can be observed from the eye diagrams represented in Fig. 3. As expected, the duty cycle ratio of the generated RZ signal increases with increasing bit rates. Some pulse distortion begins to appear at $40 \mathrm{~Gb} / \mathrm{s}$, due to a slightly nonoptimal delay. The spectra recorded in a 0.01-nm resolution bandwidth at the output of the DI are shown in Fig. 4 in the case of $20-$ and $40-\mathrm{Gb} / \mathrm{s}$ operation, together with the measured relative transmission of one of the gratings. 


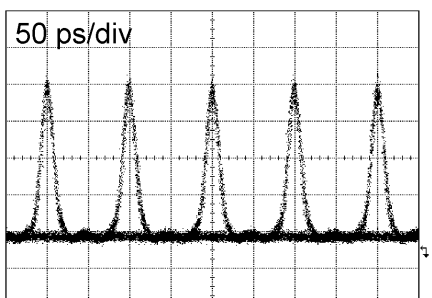

$10 \mathrm{~Gb} / \mathrm{s}$

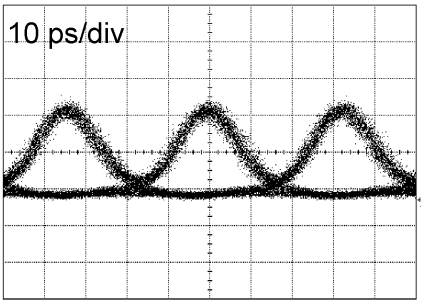

$30 \mathrm{~Gb} / \mathrm{s}$

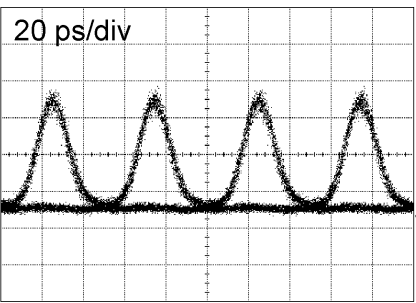

$20 \mathrm{~Gb} / \mathrm{s}$

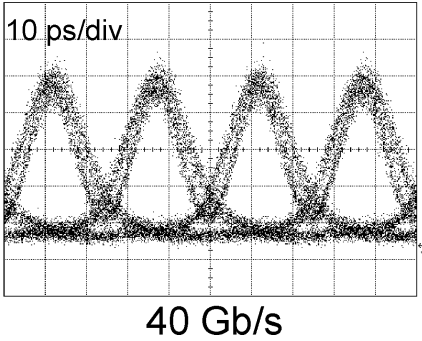

$40 \mathrm{~Gb} / \mathrm{s}$

Fig. 3. Eye diagrams of the RZ signal at the DI output for 10-, 20-, 30-, and $40-\mathrm{Gb} / \mathrm{s}$ operation.

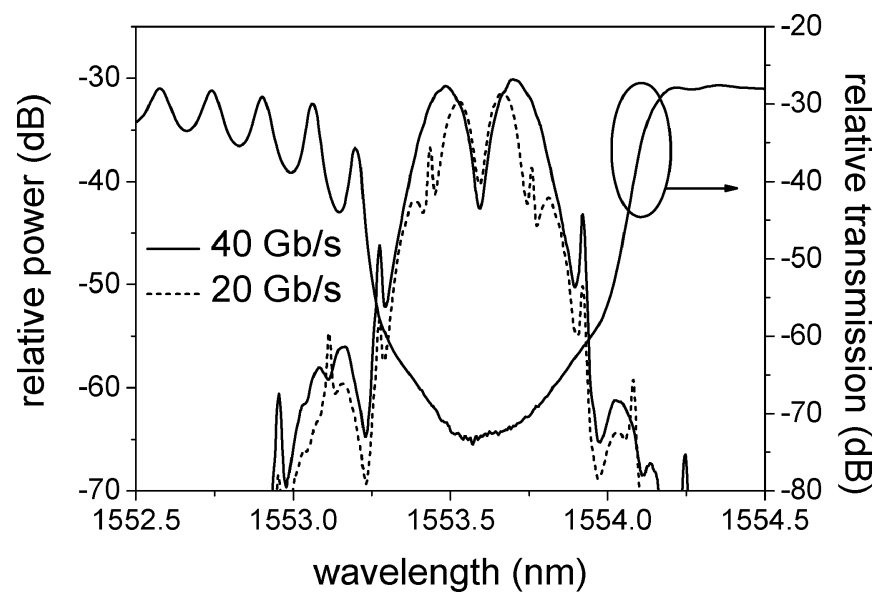

Fig. 4. Spectra of the RZ signals generated at the output of the Michelson DI at 20 and $40 \mathrm{~Gb} / \mathrm{s}$. The transmittivity of one of the grating reflectors is also represented.

They exhibit typical features of the RZ-AMI modulation format, namely a notch induced by destructive interference at the carrier frequency. Bit-error-rate (BER) curves measured at the output of the DI are shown in Fig. 5. The PRBS pattern length was $2^{31}-1$. Beyond the reduction of the bit rate and associated lower signal-to-noise ratio requirements, the reduction of the duty cycle at lower bit rates is believed to contribute to the observed improved BER performance.

\section{CONCLUSION}

A DI structure aimed at RZ signal generation using phase-tointensity modulation conversion of an NRZ signal has been realized. The device uses a Michelson interferometer structure fabricated by direct UV writing with waveguide gratings as

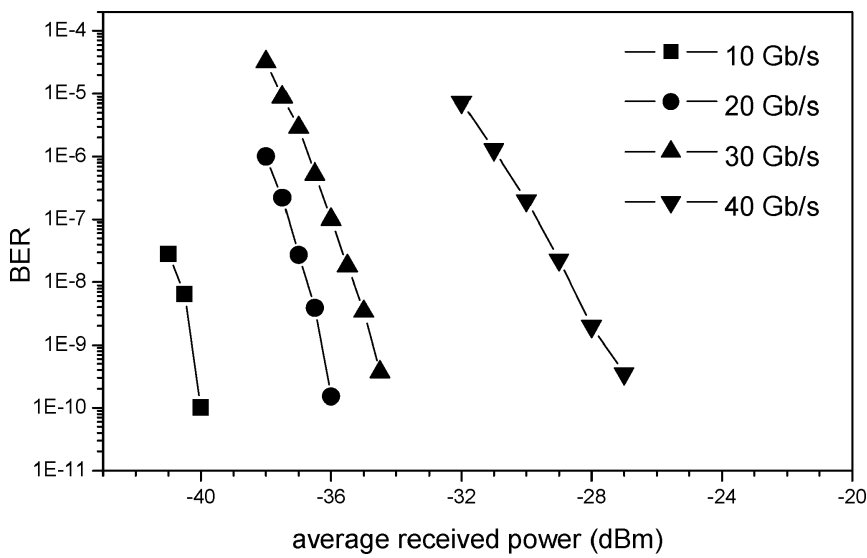

Fig. 5. BER curves for 10-, 20-, 30-, and 40-Gb/s operation.

reflective elements. Successful RZ signal generation has been verified up to $40 \mathrm{~Gb} / \mathrm{s}$. The device is compact, inherently stable, and allows for easy customization of the pulsewidth by proper positioning of the gratings on a single coupler structure. Consequently, the potential of the direct UV writing technique for fabrication of advanced components has been confirmed.

\section{REFERENCES}

[1] M. Svalgaard, "Direct UV-written integrated optical components," in Tech. Dig. Optical Fiber Communication Conf. (OFC 2004), Los Angeles, CA, Feb. 2004, Paper FK2.

[2] — , "Direct writing of planar waveguide power splitters and directional couplers using a focused ultraviolet laser beam," Electron. Lett., vol. 33, no. 20, pp. 1694-1695, Sep. 1997.

[3] G. D. Maxwell and B. J. Ainslie, "Demonstration of a directly written directional coupler using UV-induced photosensitivity in a planar silica waveguide," Electron. Lett., vol. 31, no. 2, pp. 95-96, Jan. 1995.

[4] M. Svalgaard, K. Færch, and L.-U. Andersen, "Variable optical attenuator fabricated by direct UV writing," J. Lightw. Technol., vol. 21, no. 9, pp. 2097-2103, Sep. 2003.

[5] X. Wei, A. H. Gnauck, X. Liu, and J. Leuthold, "Nonlinearity tolerance of RZ-AMI format in $42.7 \mathrm{Gbit} / \mathrm{s}$ long-haul transmission over standard SMF spans," Electron. Lett., vol. 39, no. 20, pp. 1459-1461, Oct. 2003.

[6] P. J. Winzer and J. Leuthold, "Return-to-zero modulator using a single NRZ drive signal and an optical delay interferometer," IEEE Photon. Technol. Lett., vol. 13, no. 12, pp. 1298-1300, Dec. 2001.

[7] Y. Miyamoto, A. Hirano, S. Kuwahara, M. Tomizawa, and Y. Tada, "Novel modulation and detection for bandwidth-reduced RZ formats using duobinary-mode splitting in wideband PSK/ASK conversion," $J$. Lightw. Technol., vol. 20, no. 12, pp. 2067-2078, Dec. 2002.

[8] X. Wei, X. Liu, S. Chandrasekhar, A. H. Gnauck, G. Raybon, J. Leuthold, and P. J. Winzer, " $40 \mathrm{~Gb} / \mathrm{s}$ duobinary and modified duobinary transmitter based on an optical delay interferometer," in Proc. Eur. Conf. Optical Communication (ECOC 2002), vol. 4, Copenhagen, Denmark, Sep. 2002, Paper 9.6.3.

[9] P. J. Winzer, A. H. Gnauck, G. Raybon, S. Chandrasekhar, Y. Su, and J. Leuthold, "40-Gb/s return-to-zero alternate-mark-inversion (RZ-AMI) transmission over 2000 km," IEEE Photon. Technol. Lett., vol. 15, no. 5, pp. 766-768, May 2003.

[10] M. Svalgaard, C. V. Poulsen, A. Bjarklev, and O. Poulsen, "Direct UV writing of buried singlemode channel waveguides in Ge-doped silica films," Electron. Lett., vol. 30, no. 17, pp. 1401-1402, Aug. 1994.

[11] J. Martin and F. Ouellette, "Novel writing technique of long and highly reflective in-fibre gratings," Electron. Lett., vol. 30, no. 10, pp. 811-812, May 1994. 